\title{
Increased risks of third primary cancers of non-breast origin among women with bilateral breast cancer
}

\author{
ABG Kwast ${ }^{1,2}$, L Liu ${ }^{3}$, JA Roukema ${ }^{4}$, AC Voogd ${ }^{5,6}$, JJ Jobsen ${ }^{7}$, JW Coebergh ${ }^{3,6}$, I Soerjomataram ${ }^{3}$ and \\ S Siesling ${ }^{*, 1,8}$
}

'Department of Research and Registration, Comprehensive Cancer Centre The Netherlands, PO Box 19079, 350I DB, Utrecht, The Netherlands; ${ }^{2}$ Department of Epidemiology, Biostatistics and HTA, Radboud University Medical Centre, PO Box 9101, 6500 HB, Nijmegen, The Netherlands; ${ }^{3}$ Department of Public Health, Erasmus Medical Centre, PO Box 2040, 3000 CA, Rotterdam, The Netherlands; ${ }^{4}$ Department of Surgery, St Elisabeth Hospital, PO Box 90151 , 5000 LC, Tilburg, The Netherlands; '5 Department of Epidemiology, Maastricht University Medical Centre, PO Box 5800, 6202 AZ, Maastricht, The Netherlands; ${ }^{6}$ Comprehensive Cancer Centre South, PO Box 23, 5600 AE, Eindhoven, The Netherlands; ${ }^{7}$ Department of Radiation Oncology, Medisch Spectrum Twente, PO Box 50000, 7500 KA, Enschede, The Netherlands; ${ }^{8}$ Department of Health Technology and Services Research, University of Twente, PO Box 217, 7500 AE, Enschede, The Netherlands

BACKGROUND: This study examined the risk of third cancer of non-breast origin (TNBC) among women with bilateral breast cancer (BBC; either synchronous or metachronous), focussing on the relation with breast cancer treatment.

METHODS: Risk was assessed, among 8752 Dutch women diagnosed with BBC between 1989 and 2008, using standardised incidence ratios (SIR) and Cox regression analyses to estimate the hazard ratio (HR) of TNBC for different treatment modalities.

RESULTS: Significant increased SIRs were observed for all TNBCs combined, haematological malignancies, stomach, colorectal, nonmelanoma skin, lung, head and neck, endometrial, and ovarian cancer. A I0-fold increased risk was found for ovarian cancer among women younger than 50 years $(\mathrm{SIR}=10.0,95 \%$ confidence interval $(\mathrm{Cl})=5.3-17.4)$. Radiotherapy was associated with increased risks of all TNBCs combined $(\mathrm{HR}=1.3 ; 95 \% \mathrm{Cl}=1.1-1.6$, respectively). Endocrine therapy was associated with increased risks of all TNBCs combined $(H R=1.2 ; 95 \% \mathrm{Cl}=1.0-1.5)$, haematological malignancies $(H R=2.0 ; 95 \% \mathrm{Cl}=1.1-3.9)$, and head and neck cancer $(H R=3.3 ; 95 \% \mathrm{Cl}=1.1-10.4)$. After chemotherapy decreased risks were found for all TNBCs combined $(H R=0.63$; $95 \% \mathrm{Cl}=0.5-0.87)$.

CONCLUSION: Increased risk of TNBC could be influenced by genetic factors (ovarian cancer) or an effect of treatment (radiotherapy and endocrine therapy). More insight in the TNBC risk should further optimise and individualise treatment and surveillance protocols in (young) women with BBC.

British Journal of Cancer (2012) 107, 549-555. doi:10.1038/bjc.20I2.270 www.bjcancer.com

Published online 19 June 2012

(C) 2012 Cancer Research UK

Keywords: bilateral breast cancer; third primary cancer; risk; radiotherapy; chemotherapy; endocrine therapy

Breast cancer is by far the most frequent cancer in European and North American women (Parkin et al, 2005). Owing to earlier diagnosis and improved treatment, breast cancer survival has increased, increasing the risk of metachronous breast cancer, among the survivors (Sant et al, 2001). Women with a history of breast cancer have a 2-3-fold higher risk of developing a contralateral breast cancer as compared to the general female population (Soerjomataram et al, 2005; Levi et al, 2006; Mellemkjaer et al, 2006; Schaapveld et al, 2008). In a Dutch population-based study, $18 \%$ of breast cancer patients were diagnosed with a second breast cancer in the period 1989-2006 (Liu et al, 2011). Similar results were observed among women at high risk, who either had a unilateral breast cancer or a twin sister with breast cancer; 9-18\% experienced a breast cancer event after 20 years of follow-up (Hartman et al, 2008). However, incidence

*Correspondence: Dr S Siesling; E-mail: s.siesling@iknl.nl

Received 10 February 2012; revised 10 May 2012; accepted 26 May 2012; published online 19 June 2012 declined since 1980 due to the increasing use of adjuvant therapy (Hartman et al, 2007).

Besides an elevated risk of contralateral breast cancer, several studies revealed that women with a primary breast cancer have an increased risk of developing a subsequent non-breast cancer. Increased risks were most consistently found for tumours of the ovary, endometrium, soft tissue and for leukaemia (Rubino et al, 2000; Evans et al, 2001; Soerjomataram et al, 2005; Levi et al, 2006; Mellemkjaer et al, 2006; Prochazka et al, 2006; Kirova et al, 2008; Schaapveld et al, 2008; Cortesi et al, 2009; Berrington de et al, 2010). Excess risks of melanoma of the skin and cancer of the bone, oesophagus, kidney and lung have also been reported, though less consistently (Rubino et al, 2000; Evans et al, 2001; Soerjomataram et al, 2005; Mellemkjaer et al, 2006; Prochazka et al, 2006; Schaapveld et al, 2008; Cortesi et al, 2009; Berrington de et $a l, 2010)$. Risks of subsequent non-breast cancer appears to be associated with genetic and other risk factors that are common for both, breast cancer patients with primary breast cancer experienced an increased risk of lung cancer and soft tissue sarcomas that could be attributed to radiation. Increased risks of melanoma 
of the skin, uterine cancer and leukaemia were found to be associated with the use of chemotherapy for patients older than 50 years, whereas the increased risk of endometrial cancer was related to endocrine therapy. At the same time, chemotherapy was associated with a reduced risk of colon and lung cancer for women younger than 50 years (Schaapveld et al, 2008).

However, information about the risk of third cancer of non-breast origin (third non-breast cancer; TNBC) after synchronous or metachronous invasive bilateral breast cancer (BBC) is lacking. Patients with $\mathrm{BBC}$ may have been exposed to more carcinogenic or carcino-protective cancer treatment. Moreover, a higher risk could be expected for genetic, reproductive or lifestyle-related cancers. More insight in these risks may further optimise and individualise surveillance protocols in women with BBC. Therefore, we assessed in this study the risks of TNBC after BBC in a nationwide study based on the Netherlands Cancer Registry (NCR). In addition, we studied the associations of TNBC risk with breast cancer treatment.

\section{MATERIALS AND METHODS}

\section{The cohort: BBC patients}

Patients were selected from the population-based nationwide NCR that reached complete coverage of cancer incidence in the Netherlands since 1989 (Comprehensive Cancer Centre Netherland (IKNL), 2011). Patient registration is based on notification on a weekly basis of all newly diagnosed malignancies by the automated national pathology archive and a yearly link with the national registry of hospital discharge diagnoses. In case of multiple primaries, the definition of a new primary tumour is a primary cancer that is not an extension, a recurrence or a metastasis of a known tumour, located at another anatomic site or when arising in the same anatomic site, belonging to a different histological subgroup or to a different behaviour subgroup (in situ vs invasive growth). Subsequently, information on patient and tumour characteristics and primary treatment are retrieved directly from the medical records by specially trained registrars. Staging is coded according to the tumour, node and metastasis system (TNM) classification (Wittekind et al, 2004); topography and histology are coded according to the International Classification of Diseases for Oncology (ICD-O; Fritz et al, 2000). Basic treatment information was available: whether patients were surgical treated, received radiotherapy, chemotherapy or endocrine therapy. Data on vital status and migration are annually updated through linkage with the national population demographics registry of the municipal administrations (Gemeentelijke basisadministratie). Data quality is high (Schouten et al, 1993b), and data completeness is estimated to be at least 95\% (Schouten et al, 1993a).

All women diagnosed with BBC, defined as invasive first breast cancer and a synchronous or metachronous invasive second contralateral primary breast cancer (without cancer before the first breast cancer or between the first and second breast cancer), between 1989 and 2008 in the Netherlands were selected $(n=9718)$. Bilateral breast cancer patients were excluded with a metastasis at time of diagnosis of the first or second breast cancer (stage IV, $n=909$ ), with a sarcoma of the breast either for the first or second breast cancer (morphology code 8830-9990, $n=17$ ), as well as patients who developed a third primary breast cancer after BBC $(n=40)$. In total, 8752 women with BBC were included in our study.

\section{Statistical analysis}

The patient and tumour characteristics are reported as frequencies and compared using $\chi^{2}$ test. To estimate the risks of TNBC after BBC standardised incidence ratios (SIR) were calculated. The SIR is the ratio of the observed to the expected numbers of TNBC cases. Observed numbers are the TNBC cases diagnosed during follow-up period. Patients with zero follow-up time between second breast cancer and the TNBC or the end of study period were excluded for the SIR calculation $(n=6)$. To determine the expected numbers, person years at risk by 5 -year age categories and 1-year calendar period categories were multiplied with the corresponding background cancer incidence in the general Dutch female population and then summed up. Person years at risk started at the second breast cancer diagnosis and ended at the date of TNBC diagnosis, date of death or the end of the study period (e.g., 31 December 2008), whichever came first. A SIR value higher than 1 implies an increased risk, whereas values lower than 1 suggest a decreased risk. Ninety-five per cent confidence intervals $(95 \% \mathrm{CI})$ were estimated assuming Poisson distribution of the TNBC occurrence. Standardised incidence ratios were computed for three age categories based on age at time of the second breast cancer diagnosis $(<50,50-64$ and $65+$ years $)$ and for four followup intervals since the second breast cancer diagnosis $(<1,1-5$, 6-10 and $>10$ years), and were plotted on a log scale. These subgroup analysis makes comparison with other studies possible and could give additional information in order to discuss and explain other outcomes. Tests for linear trend in relation to period of diagnosis were performed by incorporating a parameter in the relevant Poisson regression model with consecutive non-negative integer values corresponding to increasing or decreasing levels of the factor and comparing the deviance statistic with that of a model without the relevant parameter.

Multivariable Cox proportional hazard analysis was used to examine the effect of breast cancer treatment on the different TNBC risks. The follow-up time was defined as the time between the date of first breast cancer diagnosis and the date of TNBC diagnosis. Patients were censored at the date of death, migration or the end of the study period (e.g., 31 December 2008). Proportional hazards were tested for all entered variables using graphical (Kaplan-Meier plots) and statistical methods. The interval between first and second breast cancer (BCFI) appeared to be a nonproportional factor and therefore analyses were stratified by BCFI categories $(<1,1-5,6-10$ and $>10$ years $)$ using the strata option in STATA. Factors included in the model were treatment of first breast cancer (radiotherapy (no, yes), chemotherapy (no, yes), endocrine therapy (no, yes)), age at first breast cancer $(<50,50-64$ and $65+$ ), year of first breast cancer incidence (continue variable). Second breast cancer treatment variables (radiotherapy (no, yes), chemotherapy (no, yes), endocrine therapy (no, yes)) were entered to the model as time-dependent covariates, allocating patients to no second breast cancer treatment until second breast cancer occurrence.

Statistical significance was defined as a two-sided $P$-value of less than 0.05. Statistical analyses were performed in SAS version 9.2 (SAS Institute, Cary, NC, USA).

\section{RESULTS}

In the Netherlands, eligible 8752 patients were diagnosed with invasive BBC between 1989 and 2008, with a median time of 2.4 years between the first and second breast cancer (Table 1). The patients accumulated 44399 person years of follow-up since second breast cancer. Overall, 586 patients developed TNBC with a median follow-up time between the second breast cancer and TNBC of 3.9 years. Compared with patients without TNBC, patients with TNBC were significantly $(P<0.001)$ more likely to be older than 65 years at first and second breast cancer diagnosis (respectively, $40 \%$ vs $47 \%$ and $59 \%$ vs $49 \%$ ), had more often a stage I second breast cancer ( $61 \%$ vs $53 \%)$, were more often surgical treated for first and second breast cancer (respectively, 98\% vs $95 \%$ and $96 \%$ vs 92\%) and received less often chemotherapy for first and second breast cancer (respectively, 9\% vs 19\% and $9 \%$ vs $19 \%)$. 
Table I Patient and tumour characteristics of patients with bilateral breast cancer

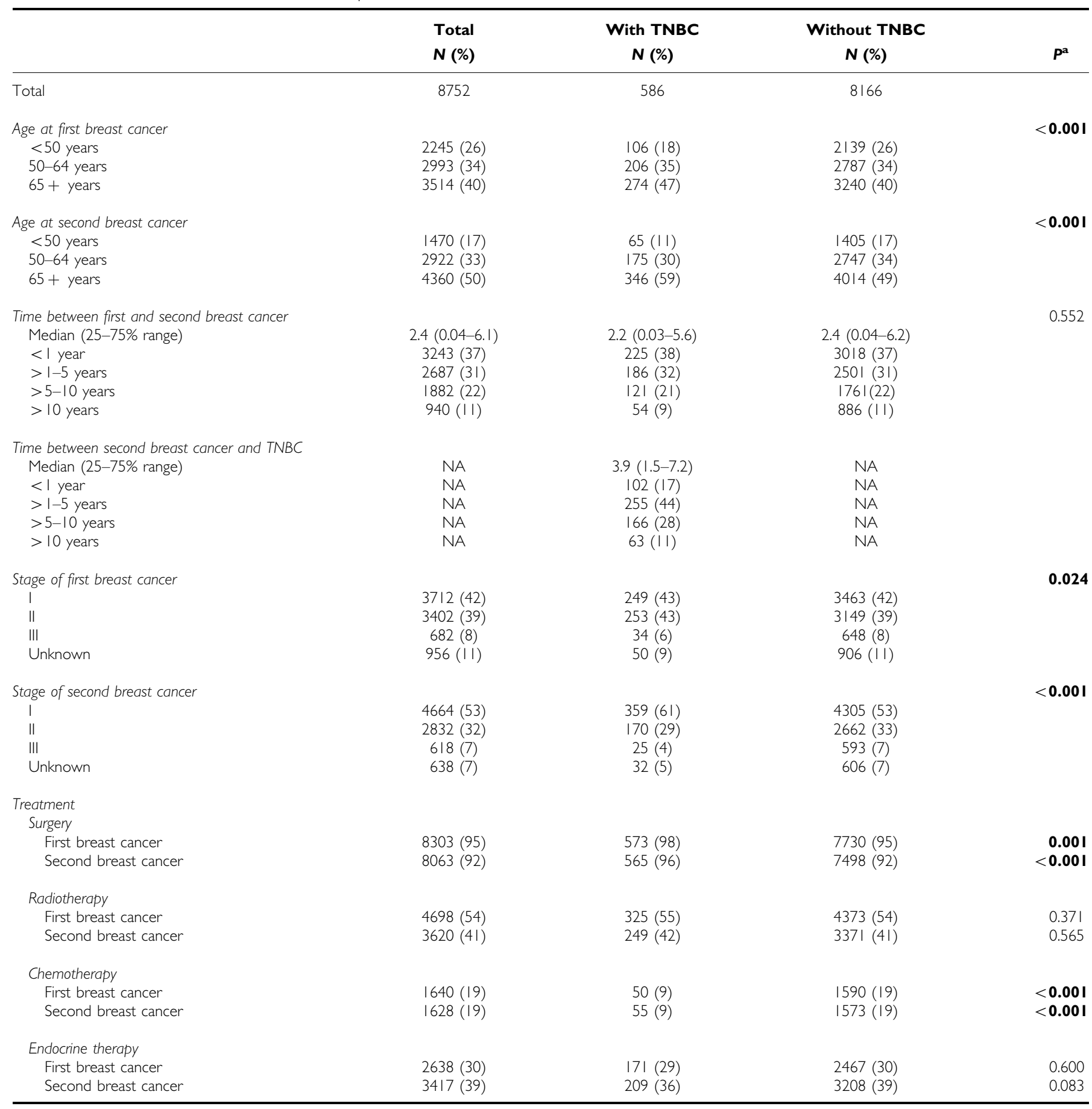

Abbreviations: $\mathrm{NA}=$ not applicable; TNBC $=$ third non-breast cancer. Bold entries denote statistical significance. ${ }^{\text {a }} P$ value $\chi^{2}$ test indicating differences between patients with and without TNBC

\section{Risk of TNBC compared with the general female population}

Table 2 shows the observed and expected numbers of TNBC and SIRs for TNBC by cancer site. The risk of all TNBCs combined after $\mathrm{BBC}$ was $1.6(95 \% \mathrm{CI}=1.5-1.7)$. Elevated risks were seen for head and neck, stomach, lung, soft tissue, non-melanoma skin, ovarian, endometrial, other female genital organs and kidney cancer, and haematological malignancies.
The risk of TNBCs overall was highest among women younger than 50 years at diagnosis of second breast cancer $(\mathrm{SIR}=2.8$, $95 \% \mathrm{CI}=2.1-3.5$; Figure 1). Differences between age groups were especially large for ovarian cancer, with a relative risk of 10 $(95 \% \mathrm{CI}=5.3-17.4)$ in women younger than 50 years at second breast cancer diagnosis. Relative risks for endometrial, stomach and kidney cancer were highest for patients older than 65 years (respective $\mathrm{SIR}=3.4 ; 95 \% \mathrm{CI}=2.3-4.5, \mathrm{SIR}=2.3 ; 95 \% \mathrm{CI}=1.4-3.6$ and SIR $=2.9 ; 95 \% \mathrm{CI}=1.6-4.9$ ). Overall, the risk of TNBCs tended 
Table 2 Observed and expected numbers and SIRs with 95\% confidence intervals for third non-breast cancers after bilateral breast cancer

\begin{tabular}{|c|c|c|c|c|}
\hline Site of TNBC & $\begin{array}{l}\text { Observed } \\
\text { numbers }\end{array}$ & $\begin{array}{l}\text { Expected } \\
\text { numbers }\end{array}$ & SIR & $95 \% \mathrm{Cl}$ \\
\hline Head and neck & 18 & 9 & 2.0 & $1.2-3.2$ \\
\hline Thyroid & 3 & 2 & 1.4 & $0.29-4.6$ \\
\hline Oesophagus & 5 & 6 & 0.84 & $0.27-2.1$ \\
\hline Stomach & 25 & 12 & 2.1 & $1.4-3.2$ \\
\hline Pancreas & 15 & 12 & 1.2 & $0.67-2.0$ \\
\hline $\begin{array}{l}\text { Liver, intrahepatic } \\
\text { bile ducts and biliary } \\
\text { tract }\end{array}$ & 7 & 5 & 1.5 & $0.60-3.2$ \\
\hline Colorectal & 91 & 74 & 1.2 & $0.99-1.5$ \\
\hline $\begin{array}{l}\text { Digestive organs, } \\
\text { other }\end{array}$ & 5 & 3 & 1.6 & $0.52-3.9$ \\
\hline Lung & 77 & 35 & 2.2 & $1.7-2.8$ \\
\hline Soft tissue & 8 & 2 & 3.6 & $1.5-7.3$ \\
\hline Melanoma of skin & 25 & 18 & 1.4 & $0.89-2.1$ \\
\hline Non-melanoma skin & 80 & 50 & 1.6 & $1.3-2.0$ \\
\hline Ovarian & 33 & 14 & 2.3 & $1.6-3.4$ \\
\hline Endometrial & 58 & 22 & 2.6 & $2.0-3.4$ \\
\hline Cervix uteri & 5 & 5 & 0.97 & $0.31-2.4$ \\
\hline Vulva & 5 & 4 & I.l & $0.36-2.8$ \\
\hline $\begin{array}{l}\text { Female } \\
\text { genitalorgans, other }\end{array}$ & 6 & i & 4.6 & $1.7-10.4$ \\
\hline Urinary bladder & 19 & 15 & 1.3 & $0.78-2.0$ \\
\hline Kidney & 20 & 8 & 2.4 & $1.5-3.8$ \\
\hline Brain & 2 & 4 & 0.50 & $0.06-2.1$ \\
\hline Haematological & 48 & 33 & 1.5 & $1.1-1.9$ \\
\hline All TNBCs ${ }^{\circ}$ & 582 & 363 & 1.6 & $1.5-1.7$ \\
\hline
\end{tabular}

Abbreviations: $\mathrm{Cl}=$ confidence interval; $\mathrm{SIR}=$ standardised incidence ratio; $\mathrm{TNBC}=$ third non-breast cancer. Bold entries denote statistical significance. ${ }^{a}$ Included, not otherwise specified and vagina. 'Included others than the specific sites denoted: renal pelvis (2 observed cases), thymus ( I observed case), eye (3 observed cases), other or unspecified sites (4 observed cases), primary sites unknown ( 10 observed cases) and benign brain tumour (7 observed cases). to slightly increase with longer follow-up time since second breast cancer diagnosis (Figure 2). Increasing SIRs over time were seen for lung and ovarian cancer and haematological malignancies. For kidney and head and neck cancer, the SIRs tended to decrease with time. No significant trends with follow-up time were found.

\section{Risk of TNBC compared within the cohort}

Table 3 shows the independent effects of cancer treatment on the risk of developing TNBC. Except for lung, ovarian and head and neck cancer, the risk of TNBC was highest in the older age patients. For lung, ovarian and head and neck cancer, a decreased risk was seen for patients older than 65 years of age (respective hazard ratio $(\mathrm{HR})=0.47 ; \quad 95 \% \mathrm{CI}=0.23-0.95, \quad \mathrm{HR}=0.13 ; \quad 95 \% \mathrm{CI}=0.03-0.49$ and $\mathrm{HR}=0.07 ; 95 \% \mathrm{CI}=0.11-0.39$ ). Chemotherapy for the first breast cancer was associated with a decreased risk of all TNBCs combined $(\mathrm{HR}=0.63 ; 95 \% \mathrm{CI}=0.45-0.87)$. After radiotherapy for the second breast cancer, increased risks were found for all TNBCs combined $(\mathrm{HR}=1.3 ; 95 \% \mathrm{CI}=1.1-1.6)$. After endocrine therapy for the second breast cancer, risks increased for all TNBCs combined $(\mathrm{HR}=1.2 ; 95 \% \mathrm{CI}=1.0-1.5)$, haematological $(\mathrm{HR}=2.0$; $95 \% \mathrm{CI}=1.1-3.9)$ and head and neck cancer $(\mathrm{HR}=3.3$; $95 \% \mathrm{CI}=1.1-10.4)$.

\section{DISCUSSION}

This is the first population-based study reporting the risks for TNBC in patients with BBC. Results showed an elevated risk for all TNBCs combined, and a more than two-fold increased risk of head and neck, stomach, lung, soft tissue, ovarian, endometrial, other female genital organs and kidney cancer was found for women with $\mathrm{BBC}$ compared with women without cancer. The risk was highest for women with BBC younger than 50 years at time of their

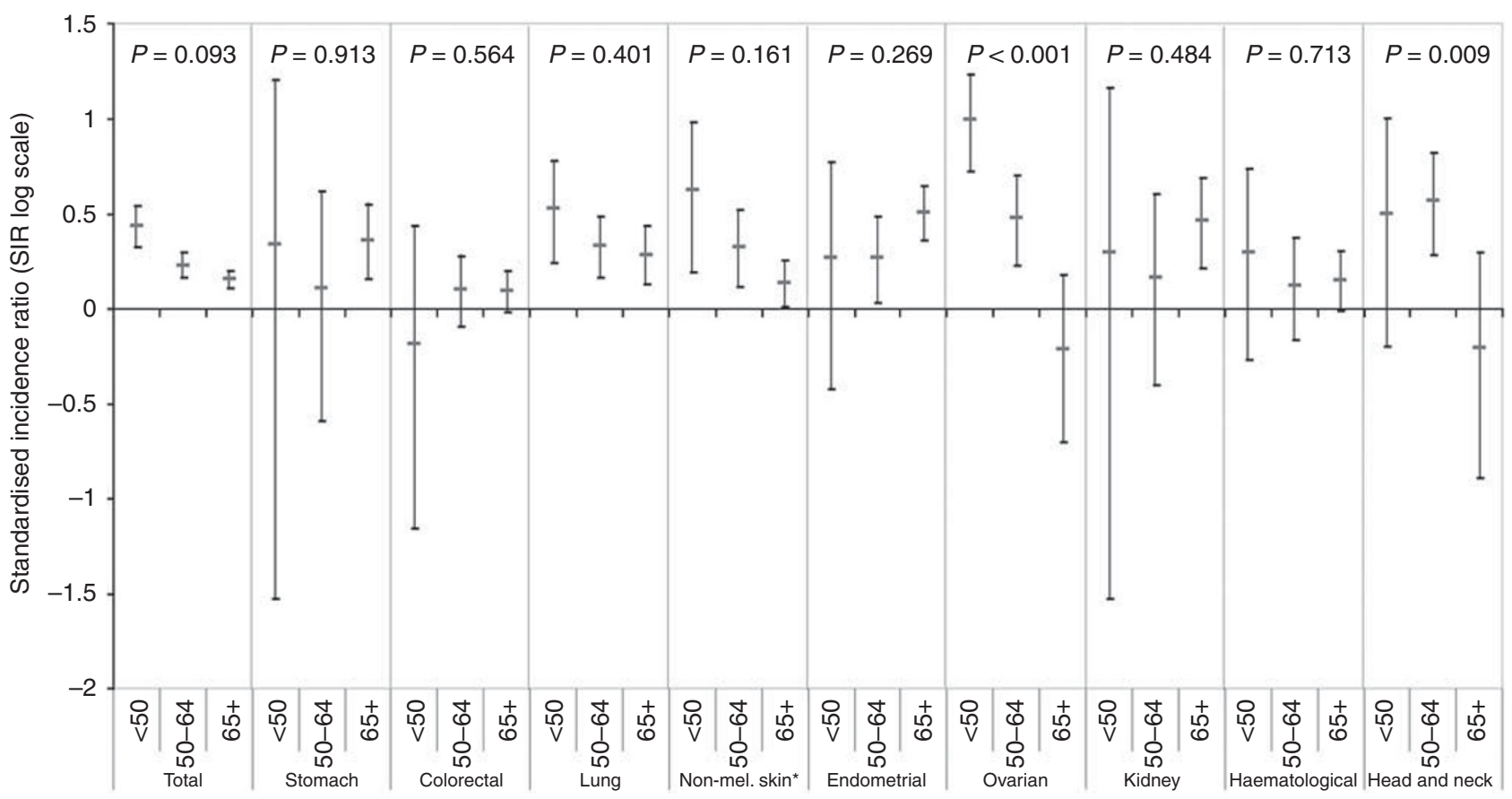

Age at second breast cancer diagnosis

Figure I SIRs, $95 \% \mathrm{Cl}$ and $P$ values for trend analyses for selected third non-breast cancers $(>10$ cases, increased SIR overall) according to the age at second breast cancer diagnosis. *Non-mel. skin = non-melanoma skin. 


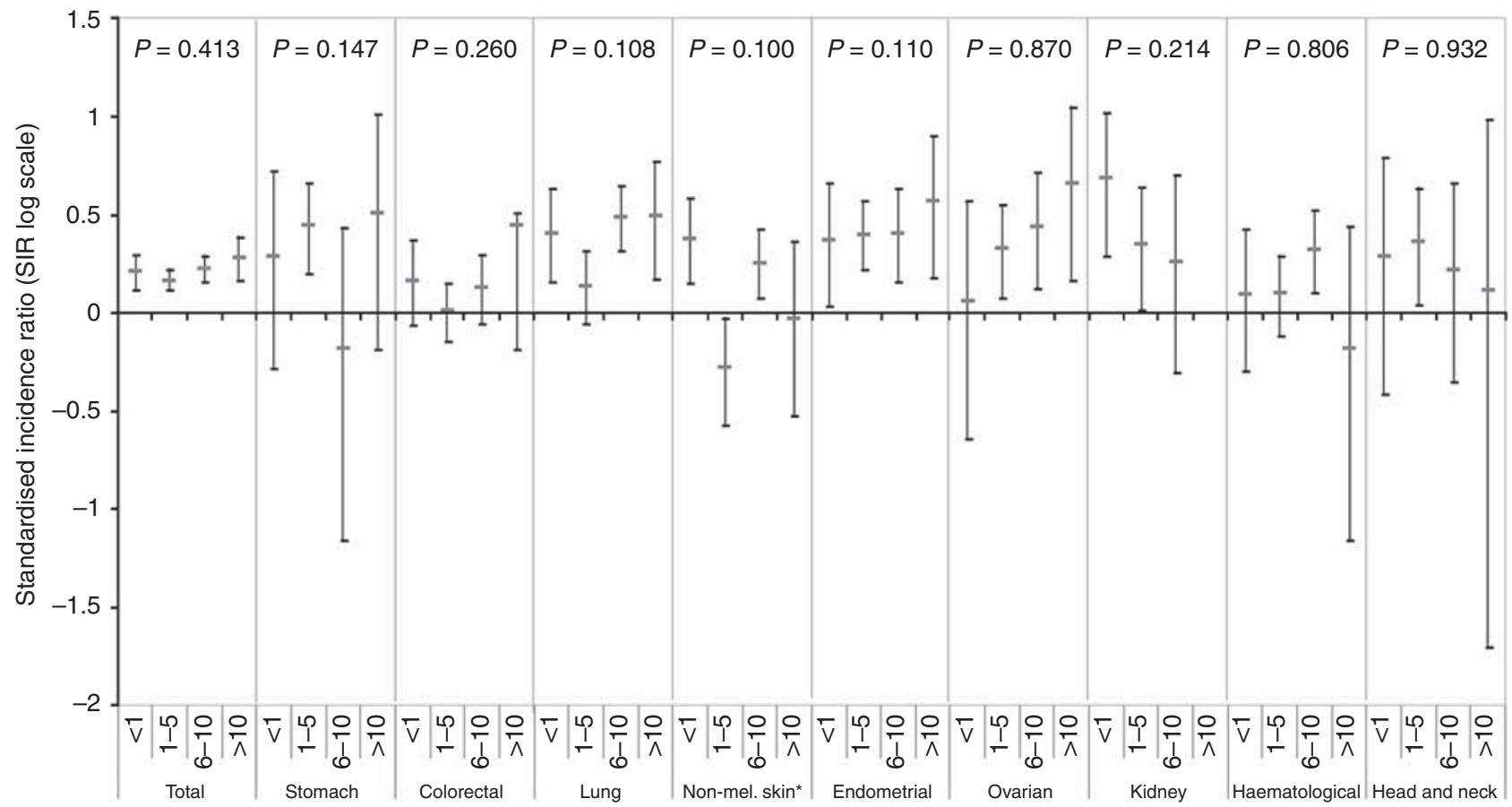

Follow-up time since second breast cancer diagnosis (years)

Figure 2 SIRs, $95 \% \mathrm{Cl}$ and $P$ values for trend analyses for selected third non-breast cancers ( $>10$ cases, increased SIR overall) according to follow-up time since second breast cancer diagnosis. $*$ Non-mel. skin = non-melanoma skin.

second breast cancer. Especially marked was the 10 -fold increased risk of ovarian cancer among young $\mathrm{BBC}$ patients. Interestingly, chemotherapy was associated with a reduced risk of all TNBCs combined.

Studies among patients with primary breast cancer reported a $23-40 \%$ increased risk of subsequent cancer (Rubino et al, 2000; Mellemkjaer et al, 2006; Cortesi et al, 2009). Our results showed an elevated risk of all TNBCs combined after BBC (SIR =1.6; $95 \% \mathrm{CI}=1.5-1.7)$, and even higher risks $(\mathrm{SIR}=2.8)$ were found in women younger than 50 years at second breast diagnosis. Other studies support higher risks for subsequent breast cancer after primary breast cancer in young women with SIRs varying from 1.3 to 5.5 (Soerjomataram et al, 2005; Mellemkjaer et al, 2006; Prochazka et al, 2006; Yu et al, 2006; Andersson et al, 2008). The high risk of TNBC in young women overall is influenced by the marked 10-fold increased risk of ovarian cancer among women younger than 50 years $(\mathrm{SIR}=10)$. This is likely related to BRCA mutations. Women with BRCA1 or BRCA2 are prone to early age breast cancer, multiple breast cancers and have a higher risk of developing an ovarian cancer (Welcsh and King, 2001).

Radiotherapy is widely used for treatment of breast cancer. Over time modern radiation techniques reduce the exposure of normal tissue around the breast. Increased risks after radiation exposure of subsequent cancers of the oesophagus, lung, thyroid gland, soft tissue and leukaemia have been earlier reported (Rubino et al, 2000; Zablotska and Neugut, 2003; Roychoudhuri et al, 2004; Levi et al, 2006; Andersson et al, 2008; Kirova et al, 2008; Schaapveld et al, 2008; Berrington de et al, 2010). Our study showed excess risk of all TNBC after BBC for patients treated with radiotherapy for the second breast cancer. Although increased risk of lung cancer was expected among women with previous radiotherapy (Zablotska and Neugut, 2003; Roychoudhuri et al, 2004; Berrington de et al, 2010), we observed no significant relation between radiation and lung cancer. We found elevated risks for lung cancer after a longer follow-up period (SIR $=3.1$ after 5 years of follow-up).
From literature it is known that there is at least a 5-year lag period between radiation exposure and cancer induction (PHASE 2 Committee to Assess Health Risks from Exposure to Low Levels of Ionising Radiation, 2006). Furthermore, Kaufman et al (2008) found no elevated risks for lung cancer among non-smoking breast cancer patients after radiotherapy. However, among ever-smokers without radiotherapy and ever-smokers treated with radiotherapy, the risk of lung cancer was significantly increased (odds ratio $(\mathrm{OR})=5.9$ and $\mathrm{OR}=18.9$, respectively). Unfortunately, no information about smoking was available in this study, hence it remains important to study the effect of radiotherapy on lung cancer taking smoking in to account.

Owing to their radiosensitivity, even ovaries, though further located from the breast, are prone to biological changes related to radiation (Rubin and Casarett, 1968). Two large studies found a relation between radiation of the breast and higher risk of subsequent ovarian cancer (Kirova et al, 2008; Berrington de et al, 2010). Although other studies found no relation (Rubino et al, 2000; Andersson et al, 2008) or even an adverse effect for women older than 50 years treated with radiotherapy (Schaapveld et al, 2008), we found a non-significant increased risk of ovarian cancer after radiotherapy for the second breast cancer.

Our results showed a decreased risk after chemotherapy for the first breast cancer for all TNBCs combined, and it may have a protective effect for colorectal, lung, ovarian and head and neck cancer. In addition, younger BBC patients had a higher risk of lung, ovarian and head and neck cancer than those older than 65 years of age. Schaapveld et al (2008) showed a protective effect of chemotherapy only among women younger than 50 years for all second non-breast cancers combined, colon and lung cancer. The study of Andersson et al (2008) found in univariable analyses a protective effect of chemotherapy for bladder cancer. Rubino et al (2000) found no risk differences of TNBC after primary breast cancer treated with or without chemotherapy; however, information on chemotherapy was lacking in this study. An explanation 
Table 3 Multivariate Cox regression analyses for the association of risk of selected third non-BC ( $>10$ cases, increased SIR overall) with BC treatment

\begin{tabular}{|c|c|c|c|c|c|c|c|c|c|c|}
\hline & $\begin{array}{l}\text { All TNBCs } \\
\text { HR }(95 \% \mathrm{Cl})\end{array}$ & $\begin{array}{c}\text { Stomach } \\
\text { HR }(95 \% \mathrm{Cl})\end{array}$ & $\begin{array}{c}\text { Colorectal } \\
\text { HR }(95 \% \mathrm{CI})\end{array}$ & $\begin{array}{c}\text { Lung } \\
\text { HR }(95 \% \mathrm{Cl})\end{array}$ & $\begin{array}{c}\begin{array}{c}\text { Non-melanoma } \\
\text { skin }\end{array} \\
\text { HR }(95 \% \mathrm{Cl})\end{array}$ & $\begin{array}{l}\text { Endometrial } \\
\text { HR }(95 \% \mathrm{CI})\end{array}$ & $\begin{array}{c}\text { Ovarian } \\
\text { HR }(95 \% \mathrm{Cl})\end{array}$ & $\begin{array}{c}\text { Kidney } \\
\text { HR }(95 \% \mathrm{Cl})\end{array}$ & $\begin{array}{c}\text { Haematological } \\
\text { HR }(95 \% \mathrm{CI})\end{array}$ & $\begin{array}{c}\text { Head and neck } \\
\text { HR }(95 \% \mathrm{Cl})\end{array}$ \\
\hline $\begin{array}{l}\text { No. of patients } \\
\text { Age at first } B C \text { diagnos }\end{array}$ & $\begin{array}{l}583 \\
\text { sis (years) }\end{array}$ & 25 & 91 & 77 & 80 & 58 & 33 & 20 & 49 & 18 \\
\hline$<50$ & । & 1 & 1 & 1 & 1 & 1 & 1 & 1 & 1 & 1 \\
\hline $\begin{array}{l}50-64 \\
65+\end{array}$ & $\begin{array}{l}1.3(1.0-1.7) \\
1.8(1.4-2.3)\end{array}$ & $\begin{array}{l}2.5(0.45-13.5) \\
\mathbf{8 . 1}(\mathbf{( 1 . 5 - 4 3 . 8 )}\end{array}$ & $\begin{array}{l}3.5(1.3-9.2) \\
6.4(2.4-17.1)\end{array}$ & $\begin{array}{c}1.0(0.58-1.8) \\
\mathbf{0 . 4 7}(\mathbf{0 . 2 3}-\mathbf{0 . 9 5})\end{array}$ & $\begin{array}{c}1.9(0.82-4.2) \\
\mathbf{4 . 6}(\mathbf{2 . 0}-\mathbf{1 0 . 6})\end{array}$ & $\begin{array}{l}2.1(0.82-5.1) \\
\mathbf{3 . 2}(\mathbf{( 1 . 2 - 8 . 3 )}\end{array}$ & $\begin{array}{c}0.63(0.29-1.4) \\
\mathbf{0 . 1 3}(\mathbf{0 . 0 3 - 0 . 4 9 )}\end{array}$ & $\begin{array}{l}1.2(0.32-4.8) \\
1.9(0.46-8.1)\end{array}$ & $\begin{array}{l}1.6(0.66-3.9) \\
2.2(0.87-5.6)\end{array}$ & $\begin{array}{c}0.45(0.14-1.4) \\
\mathbf{0 . 0 7}(\mathbf{0 . 1} \mathbf{- 0 . 3 9 )}\end{array}$ \\
\hline $\begin{array}{l}\text { Incidence year first } \\
B C\end{array}$ & $1.1(1.0-1.1)$ & $1.0(0.9 \mid-1.1)$ & I.I (1.0-I.2) & $1.1(1.0-1.2)$ & $1.1(1.1-1.2)$ & $1.0(0.93-1.1)$ & $0.93(0.84-1.0)$ & $1.0(0.88-1.1)$ & $1.1(1.01-1.2)$ & $1.0(0.9 \mid-1.2)$ \\
\hline $\begin{array}{l}\text { First BC } \\
\text { Radiotherapy } \\
\text { Chemotherapy } \\
\text { Endocrine } \\
\text { therapy }\end{array}$ & $\begin{array}{c}1.1(0.87-1.3) \\
\mathbf{0 . 6 3}(\mathbf{0 . 4 5}-\mathbf{0 . 8 7}) \\
1.0(0.82-1.3)\end{array}$ & $\begin{array}{r}1.8(0.71-5.0) \\
0.32(0.03-3.2) \\
1.2(0.43-3.5)\end{array}$ & $\begin{array}{l}0.69(0.42-1.2) \\
0.40(0.11-1.5) \\
0.63(0.34-1.2)\end{array}$ & $\begin{array}{r}0.93(0.56-1.6) \\
0.49(0.21-1.2) \\
1.2(0.66-2.3)\end{array}$ & $\begin{array}{r}1.5(0.88-2.5) \\
1.4(0.61-3.3) \\
0.69(0.37-1.3)\end{array}$ & $\begin{array}{r}0.69(0.37-1.3) \\
1.1(0.41-3.2) \\
1.4(0.70-2.7)\end{array}$ & $\begin{array}{r}1.4(0.60-3.1) \\
0.24(0.05-1.1) \\
1.2(0.38-3.5)\end{array}$ & $\begin{array}{r}1.6(0.58-4.3) \\
0.28(0.03-2.4) \\
1.7(0.60-5.0)\end{array}$ & $\begin{array}{r}1.6(0.82-3.1) \\
0.82(0.29-2.3) \\
0.62(0.27-1.4)\end{array}$ & $\begin{array}{r}2.9(0.87-9.9) \\
0.13(0.01-1.2) \\
2.0(0.54-7.3)\end{array}$ \\
\hline $\begin{array}{l}\text { Second BC } \\
\text { Radiotherapy } \\
\text { Chemotherapy } \\
\text { Endocrine } \\
\text { therapy }\end{array}$ & $\begin{array}{r}\mathbf{I . 3}(\mathbf{I . 1}-\mathbf{I . 6}) \\
0.93(0.67-1.3) \\
\mathbf{I . 2}(\mathbf{I . 0} \mathbf{1 . 5})\end{array}$ & $\begin{array}{c}1.6(0.63-4.2) \\
2.3(0.38-14.0) \\
0.66(0.22-2.0)\end{array}$ & $\begin{array}{r}1.4(0.8-2.4) \\
0.80(0.25-2.6) \\
1.5(0.87-2.5)\end{array}$ & $\begin{array}{r}1.5(0.89-2.5) \\
0.58(0.25-1.4) \\
1.08(0.61-1.9)\end{array}$ & $\begin{array}{r}1.1(0.68-1.9) \\
0.55(0.19-1.6) \\
1.6(0.94-2.7)\end{array}$ & $\begin{array}{r}1.3(0.69-2.4) \\
0.95(0.31-2.9) \\
1.5(0.81-2.9)\end{array}$ & $\begin{array}{r}1.8(0.82-4.0) \\
0.95(0.33-2.7) \\
0.57(0.20-1.7)\end{array}$ & $\begin{array}{r}0.90(0.33-2.5) \\
2.1(0.48-8.8) \\
2.3(0.86-6.1)\end{array}$ & $\begin{array}{r}1.1(0.56-2.1) \\
0.70(0.22-2.2) \\
\mathbf{2 . 0}(\mathbf{I . I}-\mathbf{3 . 9})\end{array}$ & $\begin{array}{l}0.74(0.26-2.1) \\
0.54(0.10-2.8) \\
\mathbf{3 . 3}(\mathbf{I . 1} \mathbf{- 1 0 . 4 )}\end{array}$ \\
\hline
\end{tabular}

Abbreviations: $\mathrm{BC}=$ breast cancer; $\mathrm{Cl}=$ confidence interval; $\mathrm{HR}=$ hazard ratio; $\mathrm{SIR}=$ standardised incidence ratio; $\mathrm{TNBC}=$ third non-breast cancer. Bold entries denote statistical significance.

for the protective effect might be that TNBCs undergo a growth delay from the use of chemotherapy. Especially for colon cancer fluorouracil-containing chemotherapy could be effective.

Acute myeloid leukaemia is considered as a (anthracyclinecontaining) chemotherapy-induced cancer, which can present within a few years after breast cancer diagnosis (Valagussa et al, 1994; Diamandidou et al, 1996; Chaplain et al, 2000). We observed no association between chemotherapy and increased risks for haematological malignancies, probably because this group not only contains acute myeloid leukaemia but also (non) Hodgkin's lymphoma and other types of leukaemia. Surprisingly, we found a significant higher risk of haematological malignancies for patients treated with endocrine therapy. As far as we know, this association was not earlier reported and we could not find a clear explanation for this association.

Since 1975 tamoxifen is used for the treatment of postmenopausal breast cancer in patients with positive oestrogen receptor Tamoxifen is linked to a 1.3-7.5-fold increased risk of endometrial cancer (van Leeuwen et al, 1994; Bergman et al, 2000; Polin and Ascher, 2008). Although no significant relation was found between endocrine treatment and the risk of endometrial cancer within the group of $\mathrm{BBC}$ patients, we found a two-fold elevated risk for endometrial cancer after $\mathrm{BBC}$ compared with the general female population, particularly for women older than 65 years at second breast cancer diagnosis and women treated with endocrine therapy (results not shown). However, in line with other studies, the SIR for endometrial cancer was also increased for women who received no endocrine therapy (results not shown; Schaapveld et al, 2008). Therefore, other shared risk factors like family history, reproductive factors (e.g., parity, hormone replacement treatment) or high body mass index probably contribute to the increased risk of endometrial cancer (Grady et al, 1995; Bernstein, 2002; Reeves et al, 2007; Reeves et al, 2012).

Some strengths and limitations of our study should be considered. The strengths of this study include the large population-based cohort with nearly complete follow-up data for vital status and TNBC that enables us to provide reliable estimates of TNBC risk after BBC and effects of treatment. However, information of other risk factors such as lifestyle factors, including smoking, alcohol consumption and body mass index, as well as genetic factors were not available.

Treatment information was restricted. No information was available about the specific type of radiotherapy and the doses. We found no significant differences in TNBC risks between patients treated with radiation for the first or the second breast cancer. As we included BBC patients, radiotherapy was given on different sites of the body so a cumulative effect could be expected for ovary and endometrial cancer and leukaemia, because of the equal distant to both sites and the radiosensitivity. Furthermore, information of specific endocrine therapy was not available in our database. Apart from tamoxifen, aromatase inhibitors or luteinising hormone-releasing hormone agonists have been administered. Therefore, the effect of endocrine therapy could be slightly underestimated.

Risks were estimated for the first and second breast cancer treatment. Patients with synchronous breast cancer could have received chemotherapy or endocrine therapy for both breasts; however, in fact they received only one dosage. Although the Cox regression model was corrected for BCFI and variables for second breast cancer treatment were incorporated as time-dependent covariates, outcomes need to be interpreted with caution.

\section{CONCLUSION}

Women with $\mathrm{BBC}$ had a 1.5 times higher risk of all TNBCs combined. Young women had a 2.8 times higher risk of all TNBCs combined and a 10-fold higher risk of ovarian cancer, compared with the general population, which is probably related to genetic factors. Chemotherapy was associated with a decreased risk of all TNBCs combined, whereas radiotherapy and endocrine therapy were associated with a increased risk. Next to the relations between treatment and the risk of TNBC and the possible role of genetics, shared environmental factors are likely to be involved for most elevated risks. Therefore, follow-up care should also be focussed on improving healthy lifestyle. This study gave more insight in the risks of TNBC and results could further optimise and individualise treatment and surveillance protocols in (young) women with BBC.

\section{ACKNOWLEDGEMENTS}

We would like to thank Professor LALM Kiemeney, PhD, for his valuable comments and advise. We thank the registrars of the Netherlands Cancer Registry for their effort in data gathering. This study is funded by the Dutch Cancer Society (KWF): The increasing burden of second primary cancers in the Netherlands: trend in incidence, survival and causes-of-death since 1970 (EMCR 2008-4132).

\section{Conflict of interest}

The authors declare no conflict of interest. 


\section{REFERENCES}

Andersson M, Jensen MB, Engholm G, Henrik SH (2008) Risk of second primary cancer among patients with early operable breast cancer registered or randomised in Danish Breast Cancer cooperative Group (DBCG) protocols of the 77, 82 and 89 programmes during 1977-2001. Acta Oncol 47: 755-764

Bergman L, Beelen ML, Gallee MP, Hollema H, Benraadt J, van Leeuwen FE (2000) Risk and prognosis of endometrial cancer after tamoxifen for breast cancer. Comprehensive Cancer Centres' ALERT Group. Assessment of Liver and Endometrial cancer Risk following Tamoxifen. Lancet 356: $881-887$

Bernstein L (2002) Epidemiology of endocrine-related risk factors for breast cancer. J Mammary Gland Biol Neoplasia 7: 3-15

Berrington de GA, Curtis RE, Gilbert E, Berg CD, Smith SA, Stovall M, Ron E (2010) Second solid cancers after radiotherapy for breast cancer in SEER cancer registries. Br J Cancer 102: 220-226

Chaplain G, Milan C, Sgro C, Carli PM, Bonithon-Kopp C (2000) Increased risk of acute leukemia after adjuvant chemotherapy for breast cancer: a population-based study. J Clin Oncol 18: 2836-2842

Comprehensive Cancer Centre Netherland (IKNL) (2011) Netherlands Cancer Registry, http://www.iknl.nl (accessed on 15 July 2011)

Cortesi L, De ME, Rashid I, Cirilli C, Proietto M, Rivasi F, Federico M (2009) Distribution of second primary malignancies suggests a bidirectional effect between breast and endometrial cancer: a population-based study. Int J Gynecol Cancer 19: 1358-1363

Diamandidou E, Buzdar AU, Smith TL, Frye D, Witjaksono M, Hortobagyi GN (1996) Treatment-related leukemia in breast cancer patients treated with fluorouracil-doxorubicin-cyclophosphamide combination adjuvant chemotherapy: the University of Texas M.D. Anderson Cancer Center experience. J Clin Oncol 14: 2722-2730

Evans HS, Lewis CM, Robinson D, Bell CM, Moller H, Hodgson SV (2001) Incidence of multiple primary cancers in a cohort of women diagnosed with breast cancer in southeast England. Br J Cancer 84: 435-440

Fritz A, Percy C, Jack A, Shanmugarathnam K, Sobin L, Parkin DM (2000) International Classification of Diseases for Oncology. 3rd edn. WHO: Geneva

Grady D, Gebretsadik T, Kerlikowske K, Ernster V, Petitti D (1995) Hormone replacement therapy and endometrial cancer risk: a metaanalysis. Obstet Gynecol 85: 304-313

Hartman M, Czene K, Reilly M, Adolfsson J, Bergh J, Adami HO, Dickman PW, Hall P (2007) Incidence and prognosis of synchronous and metachronous bilateral breast cancer. J Clin Oncol 25: 4210-4216

Hartman M, Hall P, Edgren G, Reilly M, Lindstrom L, Lichtenstein P, Kaprio J, Skytthe A, Peto J, Czene K (2008) Breast cancer onset in twins and women with bilateral disease. J Clin Oncol 26: 4086-4091

Kaufman EL, Jacobson JS, Hershman DL, Desai M, Neugut AI (2008) Effect of breast cancer radiotherapy and cigarette smoking on risk of second primary lung cancer. J Clin Oncol 26: 392-398

Kirova YM, de RY, Gambotti L, Pierga JY, Asselain B, Fourquet A (2008) Second malignancies after breast cancer: the impact of different treatment modalities. Br J Cancer 98: 870-874

Levi F, Randimbison L, Te VC, La VC (2006) Cancer risk after radiotherapy for breast cancer. Br J Cancer 95: 390-392

Liu L, de VE, Louwman M, Aben K, Janssen-Heijnen M, Brink M, Coebergh JW, Soerjomataram I (2011) Prevalence of multiple malignancies in the Netherlands in 2007. Int J Cancer 128: 1659-1667

Mellemkjaer L, Friis S, Olsen JH, Scelo G, Hemminki K, Tracey E, Andersen A, Brewster DH, Pukkala E, McBride ML, Kliewer EV, Tonita JM, KeeSeng C, Pompe-Kirn V, Martos C, Jonasson JG, Boffetta P, Brennan P (2006) Risk of second cancer among women with breast cancer. Int $J$ Cancer 118: 2285-2292
Parkin DM, Bray F, Ferlay J, Pisani P (2005) Global cancer statistics, 2002. CA Cancer J Clin 55: 74-108

PHASE 2 Committee to Assess Health Risks from Exposure to Low Levels of Ionizing Radiation. Health risks from exposure to low levels of ionizing radiation. Biological Effects of Ionizing Radiation VII (BEIR VII) (2006) The National Academies Press: Washington DC

Polin SA, Ascher SM (2008) The effect of tamoxifen on the genital tract. Cancer Imaging 8: 135-145

Prochazka M, Hall P, Granath F, Czene K (2006) Family history of breast cancer and young age at diagnosis of breast cancer increase risk of second primary malignancies in women: a population-based cohort study. Br J Cancer 95: 1291-1295

Reeves GK, Pirie K, Beral V, Green J, Spencer E, Bull D (2007) Cancer incidence and mortality in relation to body mass index in the Million Women Study: cohort study. BMJ 335: 1134

Reeves GK, Pirie K, Green J, Bull D, Beral V (2012) Comparison of the effects of genetic and environmental risk factors on in situ and invasive ductal breast cancer. Int J Cancer 131: 930-937

Roychoudhuri R, Evans H, Robinson D, Moller H (2004) Radiation-induced malignancies following radiotherapy for breast cancer. Br J Cancer 91: 868-872

Rubin P, Casarett GW (1968) Clinical radiation pathology as applied to curative radiotherapy. Cancer 22: 767-778

Rubino C, de VF, Diallo I, Shamsaldin A, Le MG (2000) Increased risk of second cancers following breast cancer: role of the initial treatment. Breast Cancer Res Treat 61: 183-195

Sant M, Capocaccia R, Coleman MP, Berrino F, Gatta G, Micheli A, Verdecchia A, Faivre J, Hakulinen T, Coebergh JW, Martinez-Garcia C, Forman D, Zappone A (2001) Cancer survival increases in Europe, but international differences remain wide. Eur J Cancer 37: 1659-1667

Schaapveld M, Visser O, Louwman MJ, de Vries EG, Willemse PH, Otter R, van der Graaf WT, Coebergh JW, van Leeuwen FE (2008) Risk of new primary nonbreast cancers after breast cancer treatment: a Dutch population-based study. J Clin Oncol 26: 1239-1246

Schouten LJ, Hoppener P, van den Brandt PA, Knottnerus JA, Jager JJ (1993a) Completeness of cancer registration in Limburg, The Netherlands. Int J Epidemiol 22: 369-376

Schouten LJ, Jager JJ, van den Brandt PA (1993b) Quality of cancer registry data: a comparison of data provided by clinicians with those of registration personnel. Br J Cancer 68: 974-977

Soerjomataram I, Louwman WJ, de VE, Lemmens VE, Klokman WJ, Coebergh JW (2005) Primary malignancy after primary female breast cancer in the South of the Netherlands, 1972-2001. Breast Cancer Res Treat 93: 91-95

Valagussa P, Moliterni A, Terenziani M, Zambetti M, Bonadonna G (1994) Second malignancies following CMF-based adjuvant chemotherapy in resectable breast cancer. Ann Oncol 5: 803-808

van Leeuwen FE, Benraadt J, Coebergh JW, Kiemeney LA, Gimbrere CH, Otter R, Schouten LJ, Damhuis RA, Bontenbal M, Diepenhorst FW (1994) Risk of endometrial cancer after tamoxifen treatment of breast cancer. Lancet 343: 448-452

Welcsh PL, King MC (2001) BRCA1 and BRCA2 and the genetics of breast and ovarian cancer. Hum Mol Genet 10: 705-713

Wittekind Ch, Greene FL, Hutter RVP, Klimpfinger M, Sobin LH. TNM Atlas. 5th edn (2004) Springer-Verlag: Berlin

Yu GP, Schantz SP, Neugut AI, Zhang ZF (2006) Incidences and trends of second cancers in female breast cancer patients: a fixed inception cohortbased analysis (United States). Cancer Causes Control 17: 411-420

Zablotska LB, Neugut AI (2003) Lung carcinoma after radiation therapy in women treated with lumpectomy or mastectomy for primary breast carcinoma. Cancer 97: 1404-1411

This work is published under the standard license to publish agreement. After 12 months the work will become freely available and the license terms will switch to a Creative Commons Attribution-NonCommercial-Share Alike 3.0 Unported License. 